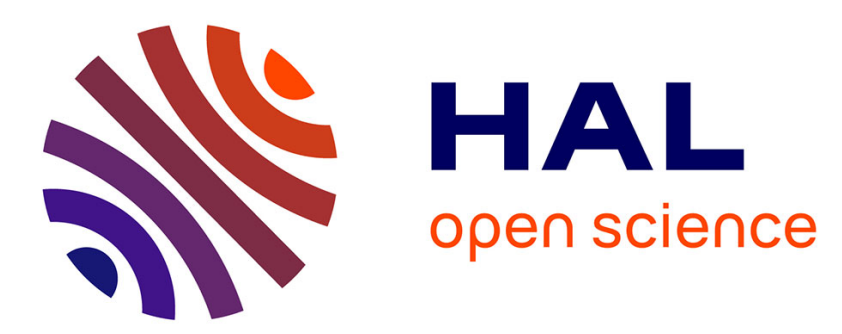

\title{
Energy efficiency policies for space heating in EU countries: A panel data analysis for the period 1990-2010.
}

\author{
Eoin Ó Broin, Jonas Nässén, Filip Johnsson
}

\section{To cite this version:}

Eoin Ó Broin, Jonas Nässén, Filip Johnsson. Energy efficiency policies for space heating in EU countries: A panel data analysis for the period 1990-2010.. Applied Energy, 2015, 150, pp.211-223. 10.1016/j.apenergy.2015.03.063 . hal-01205485v2

\section{HAL Id: hal-01205485 \\ https://hal.science/hal-01205485v2}

Submitted on 18 Jan 2017

HAL is a multi-disciplinary open access archive for the deposit and dissemination of scientific research documents, whether they are published or not. The documents may come from teaching and research institutions in France or abroad, or from public or private research centers.
L'archive ouverte pluridisciplinaire HAL, est destinée au dépôt et à la diffusion de documents scientifiques de niveau recherche, publiés ou non, émanant des établissements d'enseignement et de recherche français ou étrangers, des laboratoires publics ou privés. 


\section{TITLE:}

Energy efficiency policies for space heating in EU countries: A panel data analysis for the period 19902010.

CORRESPONDING AUTHOR FAMILY NAME:

Ó Broin ${ }^{\mathrm{a}}$,

CORRESPONDING AUTHOR FIRST NAME:

Eoin

e-mail: eoin.obroin@chalmers.se

Phone: $\quad+46317721450$

Fax: $\quad+46317723592$

CO-AUTHOR 1:

Jonas Nässén ${ }^{b}$

e-mail: jonas.nassen@chalmers.se

\section{CO-AUTHOR 2:}

Filip Johnsson $^{\mathrm{a}}$

e-mail:_filip.johnsson@chalmers.se

${ }^{\mathrm{a} D e p a r t m e n t ~ o f ~ E n e r g y ~ a n d ~ E n v i r o n m e n t, ~}$ Energy Technology,

Chalmers University of Technology, SE-412 96 Göteborg

${ }^{\mathrm{b}}$ Department of Energy and Environment, Physical Resource Theory,

Chalmers University of Technology,

SE-412 96 Göteborg 


\title{
Energy efficiency policies for space heating in EU countries: A panel data analysis for the period 1990 to 2010.
}

\section{3}

\begin{abstract}
We present an empirical analysis of the more than 250 space heating-focused energy efficiency policies that have been in force at the EU and national levels in the period 1990-2010. This analysis looks at the EU-14 residential sector (Pre-2004 EU-15, excluding Luxembourg) using a panel data regression analysis on unit consumption of energy for space heating $\left(\mathrm{kWh} / \mathrm{m}^{2} /\right.$ year). The policies are represented as a regression variable using a semi-quantitative impact estimation obtained from the MURE Policy Database. The impacts of the policies as a whole, and subdivided into financial, regulatory, and informative policies, are examined. The correlation between the actual reductions in demand and the estimated impact of regulatory policies is found to be stronger than the corresponding correlations with the respective impacts of financial policies and informative polices. Together with the well-known market barriers to energy efficiency that exist in the residential sector, these findings suggest that regulatory policy measures be given a high priority in the design of an effective pathway towards the EU-wide goals for space heating energy.
\end{abstract}

\section{Keywords}

Residential; Econometrics; Efficiency; Policy; Space heat; Regulations

\section{INTRODUCTION}

Lowering the absolute energy demand of buildings is a key policy goal of the EU. This is to be achieved mainly through improvements in end-use efficiency [1]. The indicative goal for Year 2020 is to lower primary energy demand within the EU by $20 \%$ relative to a business-as-usual scenario. This goal is part of the EU Climate and Energy Packet (known colloquially as the EU 202020 goal), and also includes the mandatory goals that by Year 2020 there should be a $20 \%$ share for renewables in the energy supply and a $20 \%$ reduction in greenhouse gas emissions (relative to the levels in Year 1990) [2]. For the residential sector, the energy savings target has been set at the higher level of $27 \%$ given the well-documented savings opportunities that exist in this sector [3]. The multifaceted motivations behind the overall energy savings goal include reducing dependence on fossil fuels imported from outside the EU, mitigating the volatility associated with oil prices, increasing competitiveness by reducing energy costs, stimulating employment in the construction sector, improving both the indoor and outdoor air quality via improved ventilation and decreased emissions of combustion gasses, reducing noise pollution, and mitigating climate change. However, studies have shown that the EU is on target to meet only half of its Year 2020 overall energy savings goal [4]. In addition, the negotiations surrounding the Energy Efficiency Directive [5] have highlighted that it is not possible to lower EU Primary Energy Demand by more than $17 \%$ using the measures agreed in the directive, meaning that a de facto $3 \%$ watering down of the savings through efficiency target has occurred. 


\section{Nomenclature}

CH Percentage of dwellings with Central Heating installed.

Delay1 Model A model used in this work in which the implementation of policies has been delayed by 1 year, to determine if there is a time lag in the impacts of efficiency policies that have been introduced.

EEW Energy Efficiency Watch Project

EP A time series variable constructed for the purpose of the present work to represent the residential sector heating-focused Efficiency Policies that are in place. $E P$ is also subdivided into financial, informative and regulatory policies in this work.

$E P B D \quad$ EU Energy Performance of Buildings Directive

ESD EU Energy Services Directive

$H A C \quad$ Heteroskedasticity and Autocorrelation Consistent Standard Errors.

$H D D \quad$ Heating Degree Days.

High-, Medium- or Low-impact Policy A policy listed in the MURE Policy Database that is estimated to reduce demand by $>0.5 \%, 0.1 \%-0.5 \%$ or $<0.1 \%$, respectively.

Laspeyres Decomposition A method of index decomposition in which model variables are each in turn changed to their final year (Year 2010) values, while the other model variables are kept at their base year (Year 1990) values. This allows the individual impact of a variable-on-demand to be estimated.

LSDV Least-Squares Dummy Variable-fixed effects panel data regression model.

MURE Policy Database An online database of all national and EU-wide sector-level efficiency policies that have been introduced in the EU-28 countries and Norway since the 1970's.

NEEAP National Energy Efficiency Action Plan

SQI Semi-quantitative impact. The name given to the ex post or ex ante evaluations of each of the policies in the MURE database. Policies are ranked as having a low, medium or high impact on the demand reduction in which they are found to or expected to result. These rankings are used in the present work to construct the $E P$, Financial, Informative and Regulatory policy variables.

Unit consumption of energy for space heating $\left(\mathrm{kWh} / \mathrm{m}^{2} / \mathrm{year}\right) \quad$ A time series variable constructed for the purpose of this work that represents the sum of each energy carrier used for heating divided by total floor area. The unit is the square metre. Unit consumption is an established indicator of energy efficiency progress, as it tracks changes in energy use related to efficiency improvement and is not influenced by changes in either population or dwelling size.

VIF Variance inflation factor. A statistical tool to detect the multicolinearity of a number of explanatory variables.

WAP Weighted Average Price. A time series variable constructed for the purpose of the present work that aggregates the prices of different energy carriers for heating into a single price weighted according to the proportion of each energy carrier in the heating mix.

Wald (F)Test A parametric statistical test used to examine the combined significance of a number of explanatory variables.

Wu-Hausman test

A statistical hypothesis test used to examine a model for endogeneity. 
Over the last decade, the European Commission has introduced a package of measures aimed at achieving the Year 2020 goal of a $20 \%$ reduction in primary energy demand. These measures include the Energy

3 Performance of Buildings Directive (EPBD) [6], the Energy Services Directive [7], the Eco Design

4 Directive [8], and the Energy Labelling of Products Directive [9]. These are policy measures that seek to

5 drive technical innovation, the diffusion of efficient technologies, and the creation of a market for

6 efficiency. More recently, additional policies that aim to improve or enhance the aforementioned factors

7 have been introduced or debated, namely, the recast of the EPBD [10], the Energy Efficiency Directive

8 [11], and the proposed Energy Taxation Directive [12]. These EU directives are transposed into national

9 policy legislation by the respective countries and complement the energy savings measures that individual

10 countries have introduced to varying degrees since the 1970's [13, 14].

11 A study that looked at 30 years of experience in OECD countries with polices for increasing energy

12 efficiency [15] revealed that most Western European countries have undergone substantial energy

13 intensity reductions, distinct from structural changes, since 1973. These authors report that many policies

14 and programs have been adopted to increase energy efficiency, and some have clearly " made a

15 difference'. The most influential policies have been energy codes, industrial voluntary agreements,

16 pricing initiatives, and financial incentives adopted at the national level, while EU-wide appliance

17 labelling and standards, and the new vehicle $\mathrm{CO}_{2}$ emissions intensity agreement also have had impacts. However, they conclude that it is very difficult to estimate what fraction of the overall energy efficiency improvement can be attributed to specific policy initiatives and what fraction is linked to other factors, such as market forces and on-going technological change.

Although thorough descriptions of the efficiency policy options in existence and their theoretical bases in terms of dealing with the well-known market barriers to efficiency are available in the literature $[14,16-$ 23], most of these studies do not quantify ex post the effects of individual or portfolios of efficiency policies. Gillingham and colleagues [18] have commented that most of the policy evaluation studies have been ex ante, and while they are useful for understanding future policies, they do not demonstrate that a policy has been effective. From a policymaker's perspective and considering the well-known market barriers to energy efficiency, it is of interest to know how well the existing and previous efficiency policy frameworks have succeeded in reducing energy demand. Previous studies of this issue, which included some ex post analyses, e.g., [24], have compared a projected baseline energy demand to the actual demand outfall and postulated that the difference is due to policy-driven energy efficiency improvements and the use of less-energy-intensive products. This approach is similar to the findings of indicator-based efficiency evaluations [25]. Vine and co-workers [26] reported that the combination of mandatory labelling which was introduced in the EU in 1992 and other efficiency policies improved the efficiency of refrigeration appliances by 10\% from 1992 to 1996. Hoicka et al. [27] showed that financial rewards can increase both the levels of participation and outcomes in efficiency programmes. As part of the IPCC $4^{\text {th }}$ assessment (AR4) chapter on mitigation options for residential/commercial buildings, a qualitative evaluation of 60 ex post efficiency case studies was carried out [28]. Appliance standards, building codes, tax exemptions, and voluntary labelling were found to be the most effective policy instruments for reducing demand. 
Using a panel of 48 of the states in the USA, Horowitz [29] examined empirically whether states with strong commitments to energy efficiency have lower levels of energy intensity than those with weak commitments, and found that this was indeed the case. He also found that energy efficiency programmes have a transformative effect on other macroeconomic variables, such as electricity price, income per capita, and technological change, and that that there are spill-over efficiency effects from states with strong commitments to efficiency towards states with weaker commitments. Filippini and colleagues [30] also used panel data methodologies to examine empirically the impacts of energy policy instruments on the estimated level of underlying energy efficiency in the EU residential sector, while Saussay et al. [31] did the same for seven EU countries and Bigano et al. [32] did the same for all sectors. The two latter studies [31 and 32] found that energy efficiency in the residential sector had been improved by the application of, in particular, mandatory standards for buildings. Filippini et al. [30] found that financial measures had the greatest impact, mandatory standards for appliances or buildings less of an impact; they found no improvement in efficiency from informative policies.

These last three cited papers [30-32] represent a discourse initiated by Bigano et al. [32] in which panel data econometric methods are used to examine the extents to which the energy efficiency-focused policies introduced across the EU have succeeded in reducing energy demand. The three papers differ from more common residential sector models in the literature, e.g. [16,33], in that they explicitly include variables that account for the introduction of energy efficiency policies. While all three papers provide valuable insights into modelling methods and the impact of efficiency policies, the method that they use for quantifying the actual efficiency policies in place is somewhat rudimentary. Bigano et al. [32] state in their conclusions that: 'It would be more interesting to use continuous instead of binary policy variables', while Saussay et al. [31] write that: 'Finally, the parameterization we chose for the building energy codes is admittedly fairly simple, and would call for further improvements'. Therefore, the present study develops the aspect regarding the modelling of efficiency policy and as such presents a further contribution to the discourse. Our focus is on the case of space heating energy demand in the EU-15 residential sector from 1990 to 2010. In addition, this paper describes other methodological developments, which are outlined in the Methodology section and expands the literature review to place the work in a broader perspective. In light of the methodological developments, the results obtained in the present work reinforce the general findings of the previous studies [30-32] regarding the paramount importance of regulatory policies as well as adding new results with regard to the impact of policy over time.This paper is divided into four sections. Following the Introduction, Section 2 presents the approach used and then describes the model parameters and the data used as inputs. This includes a description of the quantitative method used in this work to represent energy efficiency policies applied to the residential sector. Section 3 presents results for the various models and a detailed discussion on the implications and interpretations of the findings. Section 4 presents the conclusions drawn from the study. 
2 This paper uses a panel data regression approach to estimate the energy savings conferred by the policy portfolio in place across the $\mathrm{EU}^{1}$. In modelling terms, the core determinants of energy demand are defined for the purposes of this paper as: energy price; personal income; the outdoor climate; the penetration of central heating in the building stock; and a time trend, which is a linear approximation of other effects that have occurred over the studied period. The latter include autonomous technical progress, fuel switching, and structural changes. These explanatory variables are similar to those used by others $[16,37]$, except that no alternative fuel price options, such as a response to an increase in the gas price, are employed. This is because the dependent variable used in this study (space heating) is not substitutable. In considering whether to employ a fixed or random effects panel data model to account for the unobserved heterogeneity across a panel of countries, it has been argued [38] that a fixed effects model should be used. Their argument is that the selection of countries for studies such as the one described in this paper is not random, since the countries chosen are not exchangeable with other countries. Bigano et al [32] chose a fixed effects rather than a random effects panel using the same justification. Dougherty [39] has explained that if a panel is designed with OECD countries only, the countries are inherently not chosen randomly. Dougherty [39] has also presented a model choice scheme, which for the purposes of this paper would suggest the use of a fixed effects model.

In keeping with the previous studies [30-32], the present study incorporates an additional explanatory variable that represents policies aimed at reducing energy demand via efficiency. The new variable is an aggregation of relevant policies and measures introduced at the EU and national levels since the 1970's and is termed $E P$ (Energy Policies) for the purposes of modelling. By introducing this variable, the component of the time trend that otherwise would have represented efficiency policy is removed. As a development, $E P$ in the model is replaced by separate variables that represent different categories of efficiency policies, to determine which particular policy categories have had the greatest impacts on demand. For the purposes of the present work, the remaining determinants of energy demand, e.g., price, income etc., are control variables, the coefficients of which are expected to concur with those reported in the literature in terms of magnitude and polarity.

In the present work, the analysis is performed for energy demand for space heating in the residential sector. The dependent variable used in this study is unit consumption ( $\mathrm{kWh} / \mathrm{m}^{2} /$ year), as its temporal dynamic is an established indicator of energy efficiency [25]. The period examined is 1990-2010. While this interval is motivated primarily by the availability of the relevant data, it is also a historical period that is of high relevance for policymakers who are designing contemporary efficiency policies. The work carried out in [32] also used Unit Consumption as a dependant variable, while [30] looked at all energy demand and [31] examined total space heating energy demand.

\footnotetext{
${ }^{1}$ Various groups [34-36] have presented comprehensive reviews of how panel data analysis can be used for energy demand studies.
} 
1 Table 1 : Comparisons of the methodologies used in the present study and the previous studies [30-32].

\begin{tabular}{|c|c|c|c|c|}
\hline & This paper & Filippini et al. [30] & Saussay et al.[31] & Bigano et al. [32] \\
\hline Temporal Scope & $1990-2010$ & $1996-2009$ & $1990-2008$ & $1980-2006$ \\
\hline Spatial Scope & EU-15 except Luxembourg & EU-27 except Malta & $\begin{array}{l}\text { Seven EU countries: } \\
\text { Austria, Denmark, Finland, } \\
\text { France, Germany, Poland } \\
\text { and the United Kingdom }\end{array}$ & EU-15 plus Norway \\
\hline Panel Structure & Balanced & Unbalanced & Unbalanced & Unbalanced \\
\hline Panel approach & Fixed Effects & $\begin{array}{l}\text { Fixed and Random Effects } \\
\text { separately }\end{array}$ & Random Effects & Fixed Effects \\
\hline $\begin{array}{l}\text { Dependent } \\
\text { variable }\end{array}$ & $\begin{array}{l}\text { Unit Consumption } \\
\left(\mathrm{kWh} / \mathrm{m}^{2} / \text { year) of }\right. \\
\text { residential sector space } \\
\text { heating energy demand } \\
\text { from five energy carriers: } \\
\text { electricity, natural gas, oil, } \\
\text { coal and district heating. }\end{array}$ & $\begin{array}{l}\text { Total energy demand in } \\
\text { residential sector }\end{array}$ & $\begin{array}{l}\text { Sum of residential sector } \\
\text { space heating energy } \\
\text { demand from three energy } \\
\text { carriers: electricity, natural } \\
\text { gas and oil }\end{array}$ & $\begin{array}{l}\text { Unit Consumption for total energy } \\
\text { demand in residential sector }\end{array}$ \\
\hline Price variable & $\begin{array}{l}\text { WAP for heat from five } \\
\text { energy carriers coal, district } \\
\text { heating, electricity natural } \\
\text { gas and oil. }\end{array}$ & $\begin{array}{l}\text { Index of household energy } \\
\text { prices }\end{array}$ & $\begin{array}{l}\text { WAP of market prices for } \\
\text { three energy carriers: } \\
\text { electricity, natural gas and } \\
\text { oil. }\end{array}$ & Electricity prices \\
\hline $\begin{array}{l}\text { Policy Data } \\
\text { Source }\end{array}$ & MURE Policy Database & MURE Policy Database & IEA BEEP Database & MURE Policy Database \\
\hline $\begin{array}{l}\text { Policy } \\
\text { parameterization }\end{array}$ & $\begin{array}{l}\text { Index that increases by 20, } \\
10 \text { or } 1 \text { every time a High-, } \\
\text { Medium-, or Low-impact } \\
\text { policy is introduced } \\
\text { respectively. }\end{array}$ & $\begin{array}{l}\text { Separate dummy variables } \\
\text { for cases of } 1-2 \text { or } \geq 3 \text { policies } \\
\text { in a particular category that } \\
\text { are in force. }\end{array}$ & $\begin{array}{l}\text { Index that increases by } 1 \\
\text { for every year a policy is in } \\
\text { force. }\end{array}$ & $\begin{array}{l}\text { Dummy variable for each year at } \\
\text { least one policy in a particular } \\
\text { category is in force. }\end{array}$ \\
\hline $\begin{array}{l}\text { Inclusion of } \\
\text { policy variables } \\
\text { in model }\end{array}$ & Variable in panel OLS & Stochastic Frontier Approach & $\begin{array}{l}\text { Stochastic Frontier } \\
\text { Approach }\end{array}$ & Variable in panel OLS \\
\hline $\begin{array}{l}\text { Lagged effects of } \\
\text { policy variables }\end{array}$ & Up to 7 years & None & $\begin{array}{l}\text { Implicit via annually } \\
\text { increasing policy index }\end{array}$ & Up to 2 years \\
\hline $\begin{array}{l}\text { Policy Categories } \\
\text { Modelled }\end{array}$ & $\begin{array}{l}\text { Four: (i) All; (ii) Financial; } \\
\text { (iii) Informative; and (iv) } \\
\text { Regulatory }\end{array}$ & $\begin{array}{l}\text { Six: (i,ii) building standards; } \\
\text { (iii,iv) financial; (v) } \\
\text { appliances; and (vi) } \\
\text { information }\end{array}$ & One: Building Standards & 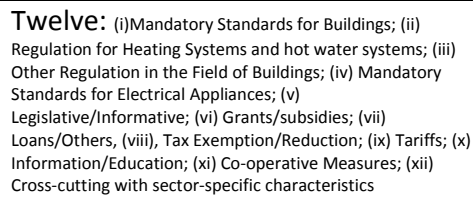 \\
\hline
\end{tabular}


Table 1 presents a comparison of the methodologies employed in the work presented in this paper and that used in the previous studies [30-32]. In summary, the present paper encompasses methodological advances that implement changes to: 1) the way that the policy data are interpreted (see Section 2.2); 2) the time period used for the analysis; 3 ) how the time series of energy prices is calculated (see Section 2.3 ); 4) the process by which the econometric testing of model results is carried out (See Section 3.1); and 5) the dependant variable used (Unit Consumption for Space Heating).

\section{$2.1 \quad$ Model description}

The linear regression model of unit consumption for space heating, $I_{i t}$, takes the form:

$$
\ln \left(I_{i t}\right)=\beta_{0}+\beta_{1} \ln \left(P_{i t}\right)+\beta_{2} \ln \left(Y_{i t}\right)+\beta_{3} \ln \left(C H_{i t}\right)+\beta_{4} \ln \left(H D D_{i t}\right)+\beta_{5}(t)+\beta_{6}\left(E P_{i t}\right)+\varepsilon_{i t}
$$

where $P_{i t}$ is a weighted average (by heating energy carrier for each individual country) real price of energy, $Y_{i t}$ is income per capita, $C H_{i t}$ is the percentage of dwellings with central heating installed, $H D D_{i t}$ are heating degree days which are a proxy variable for the outdoor climate, $t$ is a time trend, $E P_{i t}$ is a numerical representation of the energy efficiency policies in place, and $\varepsilon_{i t}$ is the residual term. The $i$ and $t$ subscripts in Eq. (1) give the spatial and temporal parameters of the panel, respectively. Initially, other choices of dependent variables for heating were tested, including the total heating demand (space heating plus water heating plus heat for cooking), total per capita, and total per square metre. However, it was decided to perform the work only for unit consumption for space heating for the EU-14 after taking into consideration the following issues: (i) data availability; (ii) the need to have a balanced panel to facilitate some statistical tests; (iii) structural differences between the newer and older Member States of the EU due to the former having had price controls in their energy markets; (iv) the research question to be answered; and (v) the preliminary results obtained. In estimating a fixed effects model, Eq. (1) is transformed to a Least-Squares Dummy Variable fixed effects (LSDV) regression model, so that the constant $\left(\beta_{0}\right)$ absorbs the individual country fixed (time invariant) effects. In addition, statistical tests are applied to the results of the (LSDV) regression model to check for: multicolinearity of the explanatory variables; the presence of inter-country spatial correlation in the dataset; and endogeneity between the $E P$ and the dependant variable.

\subsection{Quantitative representation of Efficiency Policies}

Data for the construction of the $E P$ variable in Eq. (1) were obtained from the MURE Policy Database [13]. This database includes more than 500 policies focused on energy efficiency that have been introduced since the 1970's across the 28 EU countries and Norway. The policies include the following types: (i) Financial; (ii) Fiscal/Tariffs; (iii) Informational/Educational; (iv) Legislative/Informative; (v) Legislative/Normative; (vi) Co-operative; and (vii) Unknown (as designated in the MURE Policy Database). Table 3 lists examples of some of these policy categories for the case of Austria. Previous studies [30,32] have also used the MURE Policy Database to model the effects of efficiency policies. Both investigations introduce dummy variables in their models for the years during which subcategories of policies, e.g., building regulations, are in force (See Table 1). Filippini et al. [30] represents an advance 
on the work of Bigano et al. [32] in this regard, since the former distinguishes between the number of policies implemented, i.e., it uses separate dummy variables respectively for cases of $1-2$ or $\geq 3$ policies in a particular subcategory that are in force. The work presented in this paper is an advance on both these studies [30 and 32] because it goes beyond binary representations of policies in place to represent them as a time series, which increases as more policies are introduced and decreases as policies become obsolete (Figure 1).

The MURE Policy Database also provides a semi-quantitative impact (SQI) ranking of each policy contained therein. These SQI rankings have been carried out by the respective energy agencies in each country that are responsible for the policy content of the database and are based on an estimation of the energy savings achievable or achieved by each policy. These SQI's are grouped into three bands, high, medium and low, depending on whether they describe policies that are expected or that have been found to reduce energy demand in their sector of focus by $>0.5 \%, 0.1 \%-0.5 \%$, and $<0.1 \%$, respectively. For example, a low impact policy as designated in the MURE Policy Database is one that has been found to lower or is expected to lower demand by less than $0.1 \%$. It is these SQI's that are used to construct the policy time series [EP in Eq. (1)] used in this paper. This solution is similar to that adopted by Berry [40], who used the American Council for an Energy-Efficient Economy's (ACEEE's) 2006 efficiency scorecard for US States as a variable in a regression function for electricity sales.

In order to construct a time-series variable that represented efficiency policy in place, it was initially thought that each policy could in turn be assigned values of 5, 2.5, and 1 for each year that they were in force, corresponding to the three SQI impact bands described above. However, an examination of the qualitative descriptions of specific policies that accompany each SQI revealed that policies rated as low impact are usually associated with very low expected savings in comparison to medium-impact and highimpact policies. Therefore, for the purposes of the present work, the three bands are assigned values of 20, 10 , and 1, respectively. In other words a policy classed as a medium impact policy in the MURE Policy Database is assumed to lead to a ten times higher demand reduction than a low impact policy. This grading scheme is applied to all categories of policy and all countries. Thus, for the example of Austria shown in Table 3, the first named policy, a Residential building subsidy, is assigned a value of 20 for every year from 1990 to 2010, as its SQI from the database ranks it as a High Impact Policy. Similarly, the second policy listed is assigned a value of 20 for each year from 1992 to 2010, while the third policy listed is assigned a value of 1 for the years 2009 and 2010 .

Taking the case of France, two low impact policies (FRA6 and FRA28) have SQI's that estimate reductions in demand of $0.01 \%$ and $0.02 \%$, respectively. Four medium-impact polices (FRA9, FRA16, FRA18, FRA44) have SQI's that estimate reductions in demand of $0.35 \%, 0.36 \%, 0.46 \%$, and $0.14 \%$, respectively. Three high-impact policies (FRA5, FRA7, and FRA8) have SQI's that estimate reductions in demand of $2.25 \%, 0.55 \%$, and $1.40 \%$, respectively. Thus, for France, the medium-impact policies are in general estimated to have a ten-fold greater impact on demand than the low-impact policies, while the high-impact policies are estimated to have 1-16-fold greater impacts than the medium-impact policies. An examination of Finland and Germany revealed differences in the SQI's of the medium- and high-impact policies at the higher end of the 1-16-fold range highlighted for France. Italy, Greece, and the UK were closer to the lower end of the range for France. Following calibration tests using the averages of the 
differences between the SQI's of high-, medium-, and low-impact policies, the aforementioned values of 20,10 , and 1 , respectively, were chosen.

No distinction is made between say a medium-impact financial policy in Austria and one in another country, despite the fact that for Austria this could amount to a Heating cost settlement for common thermal facilities (see Table 3), whereas for say France, a medium-impact financial policy could amount to a zero-rated eco-loan (FRA 31). Distinguishing between policy types at a national level would increase significantly the level of disaggregation in the model and would represent a deviation from the focus on improving the representation of policies heretofore implemented in previous studies [30-32]. Nevertheless, this is an area that warrants further research. As the $E P$ time series in Eq. (1) is an aggregation of the high, medium-, and low-impact policies, the $\beta_{6}$ term in Eq. (1) represents the actual demand reduction achieved from the expected (SQI) impact of a low-impact policy.

For the 14 countries that are in focus in the present work, the database contains 329 residential sector policies. Of these, six are defined as cross-cutting, and therefore are excluded from the work because they represent energy and carbon taxes of various types that would already be represented in the energy price time series $\left(P_{i t}\right)$ in Eq. (1). Similarly, 15 regionally focused polices in Belgium, e.g., Flanders or Wallonia, were not included, whereas federal policies for the same country were included. In addition, 48 policies that focus exclusively on electricity demand for appliances and lighting were also ignored. Of the remaining 260 policies, 202 are focused on heat and 58 are focused on both heat and electricity (See Table 2). An example of the latter is a policy named "Energy advice for households", which obviously applies to both heating and other household uses of energy.

Table 2 : Numbers of policies from the MURE Policy Database analysed for the purpose of the present work ${ }^{\mathrm{a}}$

\begin{tabular}{|l|c|c|c|}
\hline Policy type & Heat & $\begin{array}{c}\text { Electricity } \\
\text { and heat }\end{array}$ & Total \\
\hline Financial & 67 & 12 & 79 \\
\hline Informative & 54 & 14 & 68 \\
\hline Regulatory & 81 & 32 & 113 \\
\hline Total & 202 & 58 & 260 \\
\hline
\end{tabular}

As mentioned earlier, the database of policies and the variable EP are divided into different categories of efficiency policy, to evaluate their respective impacts. The categories chosen are: regulatory, economic, and information policy instruments [41]. According to [42], this classification is based on the degree of authoritative force. Regulations imply commanding particular behaviours; economic instruments aim at altering the benefits and/or costs in order to encourage energy efficiency investments; and, finally, information aims at shifting priorities by building awareness. Several assumptions were needed to apply this categorisation to the policies in the MURE Policy Database. Although policies that are labelled 'Legislative/Informative' are regulatory, in that they mandate the display of information, these policies have been categorised as informative, since market transformation via information is their main goal. Most of the policies in this category refer to the EU EPBD and the Energy Labelling of Products directives $[6,9]$. While the EU EPBD directive contains regulatory components, such as the mandatory 
inspection of boilers, the main focus of both directives is the energy labelling of buildings and appliances,

2 respectively. Policies in the database categorised as 'Co-operative' or 'Unknown' were each examined in

3 turn to define their placements. Although the Co-operative policy shown in the example for Austria (Table

42 ) is ostensibly information-driven, its main contribution with respect to the residential sector is in

5 relation to minimum standards for standby, which makes it a regulatory policy for the classification

6 applied in this work. For some countries, notably, the Netherlands, many of the policies listed are labelled

7 as 'Co-operative'. This is because in the Netherlands, there is strong representation of housing

8 organisations, which make voluntary agreements with the authorities to reduce energy demand. Each of

9 these polices have been categorised on an ad hoc basis to determine if they are more regulatory or

10 informative in nature. Policies labelled Financial, i.e., grants for renewables, were included. Many of these

11 refer to grants or subsidies for the installation of heat pumps and solar photovoltaic (PV) or collector

12 panels, all of which would reduce the final energy demand, as listed in the energy statistics. Table 2 shows

13 the numbers of policies for each category based on the categorisation carried out for the present work.

14 Most of these policies were implemented in the period 1990-2010, while others were already in force in

151990.

Table 3 : Residential sector energy efficiency policies for Austria from the MURE Policy Database [13] analysed in the present work. ${ }^{a}$

\begin{tabular}{|c|c|c|c|c|c|c|c|c|}
\hline Designation $^{b}$ & Focus $^{b}$ & Weight $^{\mathrm{b}}$ & Policy Title & Policy Type & $\mathrm{SQ} l^{\mathrm{C}}$ & Duration $^{c}$ & $\mathrm{EU}^{\mathrm{C}}$ & Code $^{c}$ \\
\hline \multirow{3}{*}{ Financial } & Heat & 20 & Residential building subsidy & Financial & High & 1989- & No & AU13 \\
\hline & Heat & 20 & Grants for renewable energy (heat pumps, biomass etc.) & Financial & High & 1992- & No & AU10 \\
\hline & Heat & 1 & National recovery plan / renovation voucher & Financial & Unknown & 2009- & No & AU26 \\
\hline \multirow{4}{*}{ Regulatory } & Heat & 20 & Heating system design standards & Legislative/Normative & High & 1989- & No & AU6* \\
\hline & Heat & 20 & Minimum thermal standards for buildings & Legislative/Normative & High & 1991- & No & AU5 \\
\hline & Heat & 10 & Heating cost settlement for common thermal facilities & Legislative/Normative & Medium & 1992- & No & AU8 \\
\hline & Elec & 1 & EU-related: Energy Labelling (Energy Star) & Co-operative Measures & Unknown & Unknown & Yes & $\mathrm{AU} 22^{*}$ \\
\hline \multirow{7}{*}{ Informative } & Heat & 20 & EU-related: EPBD - Building Energy Certificates & Legislative/Informative & High & 2008- & Yes & AU21 \\
\hline & Heat & 20 & Klima:Aktiv Building - new standards for buildings & Information/Education & High & 2005- & No & AU18 \\
\hline & Heat & 10 & "Wohnmodern" support for large apartment renovation & Information/Education & Medium & 2006- & No & $\mathrm{AU} 19 *$ \\
\hline & $\begin{array}{l}\text { Heat and } \\
\text { Electricity }\end{array}$ & 1 & Energy advice for households & Information/Education & Unknown & $1990-$ & No & $\mathrm{AU} 27$ \\
\hline & Elec & 1 & topprodukte.at, Platform for energy-efficient appliances & Information/Education & Low & 2005- & No & $\mathrm{AU} 17^{*}$ \\
\hline & Elec & 1 & Smart Metering and Informative Billing & Information/Education & Unknown & 2008- & No & AU28 \\
\hline & Elec & 10 & EU-related: Energy Labelling of Household Appliances & Legislative/Informative & Medium & 1994- & Yes & AU1 \\
\hline \multicolumn{9}{|c|}{${ }^{\mathrm{a}}$ Since the completion of the work described in this paper, the MURE Policy Database has been reorganised. For the example of Austria given in } \\
\hline 19 & \multicolumn{8}{|c|}{ this table, the reorganisation has resulted in the removal of the policies marked with an asterisk and the relabeling of all household-focused } \\
\hline 20 & \multicolumn{8}{|c|}{ policies with the prefix HOU, e.g., HOU-AU13 for the first policy listed in the table. See: http://www.measures-odyssee-mure.eu/ } \\
\hline 21 & \multicolumn{8}{|c|}{${ }^{\mathrm{b}}$ These designations (categories) are assigned as part of the present work. } \\
\hline 22 & \multicolumn{8}{|c|}{${ }^{\mathrm{c}}$ These items are derived from the MURE Policy Database. } \\
\hline
\end{tabular}

23 As an example, for Austria, the database includes nine heat-focused energy efficiency measures, four

24 electricity efficiency-focused measures, and one measure that covers both heat and electricity. These

25 fourteen policies were introduced between 1989 and 2009 and are all still in force (Table 3). Six of the

26 Austrian measures have received a high SQI, three have received a medium score, one a low score, and

27 four have had their SQI graded as "Unknown". The policies without an SQI ranking are assumed to have a

28 low impact on demand. The fourteen policies are divided into the Financial (Fin), Regulatory (Reg), and 
Informative (Info) categories in line with the categorisation used in the present work, although those that focus exclusively on electricity are not included in the subsequent analysis. Columns 1 and 2 of Table 3 show the categorisation of the policy measures applied by the authors of this paper, while the remaining columns are based on data from the MURE Policy Database [13]. Thus, Policy Type and SQI are MURE categorisations for each measure. As all the measures are still in force, the column Duration gives the starting year of the policy measure. The column that follows Duration indicates whether the measures were the result of an EU directive or not, while the last column lists the MURE Policy Database codes for Households.

Figure 1 shows the cumulative SQI ranking of the 260 polices analysed in this work. The difference between the numbers shown in Table 2 and those shown in Figure 1 is that rather than show the number of policies in force for the EU-14, the latter takes into account the different rankings assigned to each policy in the MURE Policy Database (high-, medium-, and low-impact policies) and also the years in which each policy was in force. Thus the y-axis of Figure 1 represents the cumulative value of the SQI of the policies in force in each of the three categories for the 14 countries analysed in this work (cf a high-impact policy in force is assigned a value of 20 , a medium-impact policy gets a 10 , and a low- or unknown-impact policy gets a values of 1). It is clear that informative polices have the lowest expected impact until Year 2006 when they catch up with the regulatory policies. A pattern of decreasing impact, e.g., from 1998 to 1999 for regulatory policies, reflects the fact that some policies in this category became obsolete in 1998 .

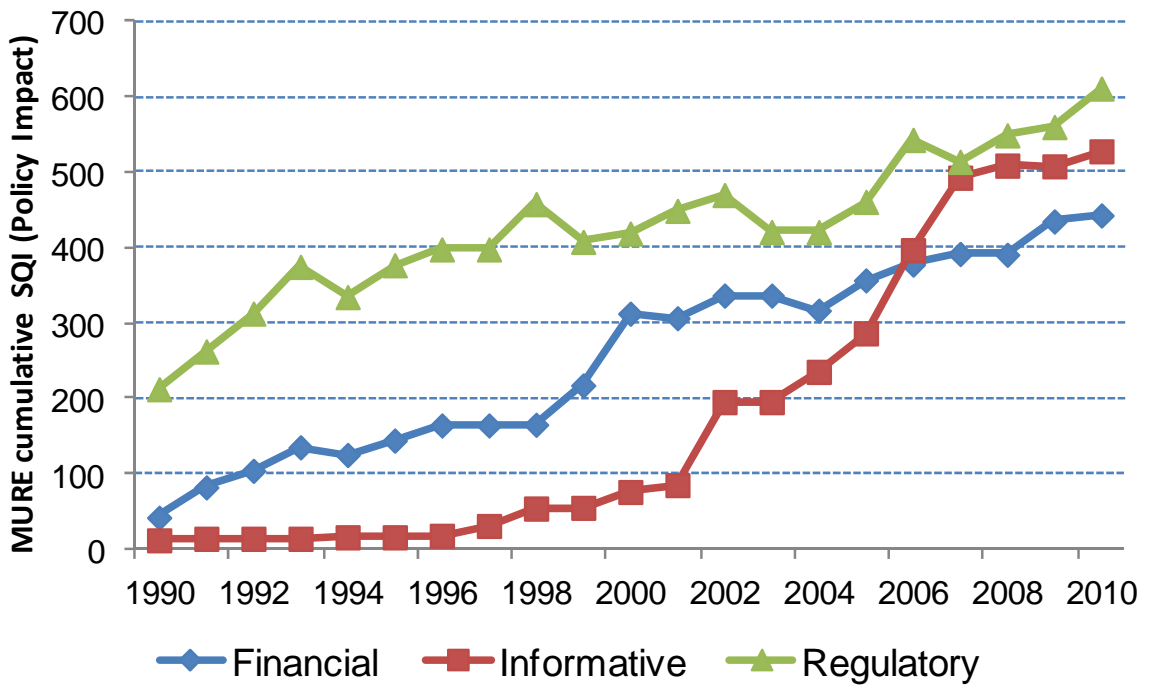

Figure 1 : Estimated level of impact of each policy category on space heating in the residential sector for the 14 EU countries analysed in this work.

As it may take several years for the impacts of policies introduced to be realised in terms of energy demand reductions, the $E P$ variable is tested with delays of up to 7 years. This approach of effectively lagging the $E P$ variable also removes the possibility of endogeneity between $E P$ and $I$ for the lagged cases. Bigano et al. [32] and Saussay et al. [31] also incorporated delayed impacts of policies (See Table 1). 
Taking the example of Austria (Table 3), the two pieces of legislation introduced in 1989 would not kickin in the Delay7 scenario until Year 1996, while the six pieces of legislation introduced after Year 2005 would not be included in the regression. Note also that in the case of Austria, the flagship EU legislation on energy efficiency in buildings, the EPBD, was only incorporated into policy legislation in Year 2008, which means that its effect, as defined in the empirical examination carried out in this work, is limited.

\subsection{Data sources for other determinants}

The data for Eq. (1) for the core determinants of space heating energy demand were obtained from the following sources: income [national private consumption in Euro]; population; average floor area per dwelling; number of permanently occupied dwellings; $H D D$, energy demand for six energy carriers [coal, oil, gas, district heating, biomass, electricity] for space heating [43]; consumer price indices [private final consumption expenditure deflator] [44]; Harmonized Indices of Consumer Prices (HICP) [45]. Income was divided by population to derive the per capita values. The heating demand data were divided by the total floor area (average floor area per dwelling times the number of permanently occupied dwellings) to derive the heating demand per square metre (unit consumption). IEA [46] provides a time series of prices for the residential sector for coal, oil, gas, and electricity normalised to Year 2005 prices ( $\epsilon_{2005} /$ toe), while Werner [47] supplies the time series of prices for district heating. These latter prices were normalised to Year 2005 prices using price indices from the OECD [44] and Eurostat [45].

Combining the time series of prices for these five energy carriers with the corresponding time series of their usage for space heating, from the Odyssee database [43], allowed a Weighted Average Price (WAP) of energy for space heating to be constructed. As a ton of oil equivalent (toe) of oil does not produce the same amount of heat as a toe of natural gas or coal (given their different conversion efficiencies when used in household boilers), the IEA prices for oil, natural gas, and coal were divided by a factor of 0.78 , 0.85 , and 0.64 [48], respectively, to obtain the prices of heat from these respective energy carriers prior to their inclusion in the $\mathrm{WAP}^{2}$. Prices for biomass for the respective countries are not available in national statistics due to the nature of the trade in this commodity. Thus, the options were to include biomass in the energy demand time series $\left(I_{i t}\right)$ but not in the weighted average energy price time series or to omit biomass from the energy demand time series; best-fit modelling indicated that the latter option was best. This price time-series thus provides a more accurate estimation of the actual price paid by households for residential sector energy demand than those used in [30-32] (See Table 1).

For Finland (1990-1994) and Portugal (1990-1999), no data were available from [43] on the demand for residential sector electricity and space heating respectively. In these two cases, time series for residential sector electricity and total energy demand obtained from [46] and [43] respectively were used to extrapolate the missing data. Prices for district heating were not available for most countries for 2009 and 2010. To obtain a complete time series, the district heating prices for each country for Year 2008 were

\footnotetext{
${ }^{2}$ These three conversion efficiencies were kept constant for the period of the study. This is due to the assumption that improvements in boiler efficiency over the period were marginal in terms of their impact on overall space heating demand [49].
} 
increased by a factor that corresponded to the change in price of the main heating fuel of the specific country for the period 2008-2010. The justification for this approach is that although district heating can be cheaper than alternative heating fuels, its price is usually maintained just below that of its main competitor.
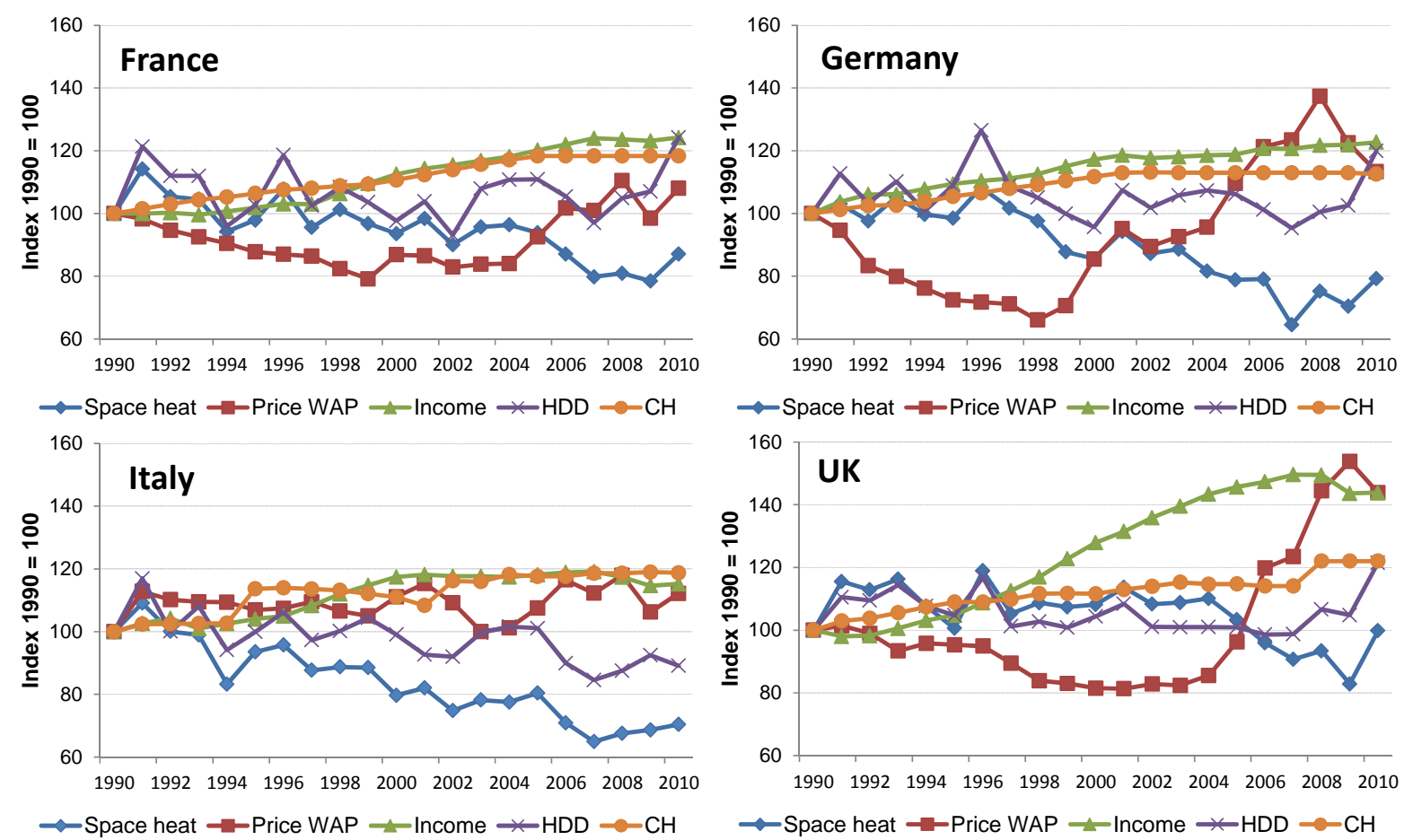

$\sim$ Space heat $\rightarrow$-Price WAP $\_$Income $*$ HDD $\multimap-\mathrm{CH}$

\section{Figure 2 : Index of space heating demand and determinants of its dynamics (including $H D D$ and penetration of central heating) for four large EU countries.}

Figure 2 shows the index of unit consumption for space heating demand and for four determinants of energy demand from Eq. (1) for France, Germany, Italy, and the UK, i.e., four of the largest countries of the EU (by demand and population). The dynamics of the variables over the period (Figure 2) shows that unit consumption has been falling since 1990 and that it tracks $H D D$, with spikes for colder years. Year 2010 would appear to have been a very cold year in France, Germany, and the UK. Income per capita and the penetration of central heating have been rising steadily, with the exception of the UK where there was an increase of $>50 \%$ in income per capita between 1993 and 2008 followed by a fall after the recession. In France, Germany, and the UK, energy prices fell in the 1990's and rose in the 2000's, although prices in Italy remained fairly stable for the entire period. In the four countries shown in Figure 2, the penetration of central heating increased by approximately $20 \%$ between 1990 and 2010. By Year 2010, the penetration of central heating in the residential sector was $>90 \%$ in all of the countries examined in the present study, with the exceptions of Greece, Portugal, and Spain [43]. 


\section{$1 \quad 3 \quad$ RESULTS AND DISCUSSION}

2 This section presents the results of the linear regression of Eq. (1) and discusses the findings in relation to

3 similar studies in the literature. The impacts on demand of the individual variables of Eq. (1) are also

4 described.

$5 \quad 3.1 \quad$ Space heating demand per square metre in the period 1990-2010

6 Table 4 presents the coefficients and test statistics, calculated for the model of space heating demand per

7 square metre using Eq. (1), for the 14 EU countries examined in the present work.

8 Table 4 : Elasticity coefficients calculated in models of space heating demand per square metre. The basic model

9 is fitted without any variable for EP. The other models include an EP variable without delay (0) and with delays of $10 \quad 1,3,5$, and 7 years respectively ${ }^{a}$.

\begin{tabular}{|c|c|c|c|c|c|c|}
\hline Parameter & Basic Model & Delay0 & Delay1 & Delay3 & Delay5 & Delay7 \\
\hline & $-0.16^{* *}$ & $-0.17 * *$ & $-0.18 * *$ & $-0.17 * *$ & $-0.15^{* *}$ & $-0.15^{* *}$ \\
\hline$\beta_{1}$ (Price) & $(0.077)$ & $(0.076)$ & $(0.076)$ & $(0.076)$ & $(0.074)$ & $(0.068)$ \\
\hline & 0.31 & 0.32 & 0.30 & 0.27 & 0.27 & 0.23 \\
\hline$\beta_{2}$ (Income) & $(0.27)$ & $(0.26)$ & $(0.25)$ & $(0.24)$ & $(0.24)$ & $(0.24)$ \\
\hline & $0.56 * * *$ & $0.59 * * *$ & $0.60 * * *$ & $0.59 * * *$ & $0.54 * * *$ & $0.53 * * *$ \\
\hline$\beta_{3}$ (HDD) & $(0.19)$ & $(0.16)$ & $(0.16)$ & $(0.17)$ & $(0.16)$ & $(0.15)$ \\
\hline$R,(C H)$ & 0.29 & 0.27 & 0.25 & 0.23 & 0.26 & 0.27 \\
\hline$p_{4}$ (しn) & $(0.27)$ & $(0.25)$ & $(0.24)$ & $(0.21)$ & $(0.22)$ & $(0.22)$ \\
\hline R. (Trend) & $-0.018 * * *$ & $-0.015 * * *$ & $-0.013 * *$ & $-0.011 * *$ & $-0.013 * * *$ & $-0.012 * *$ \\
\hline$\beta_{5}$ (Trend) & $(0.0053)$ & $(0.0054)$ & $(0.0056)$ & $(0.0048)$ & $(0.0047)$ & $(0.0051)$ \\
\hline $\boldsymbol{R}$ (FP) & (a) & -0.00071 & -0.0011 & $-0.0017 * *$ & $-0.0021 * * *$ & $-0.0025^{* * *}$ \\
\hline$\beta_{6}(\mathrm{EP})$ & -- & $(0.00086)$ & $(0.00085)$ & $(0.00076)$ & $(0.00068)$ & $(0.00073)$ \\
\hline$\beta_{0}$ Constant & 31.76 & 24.44 & 20.52 & 18.37 & 21.48 & 20.12 \\
\hline $\operatorname{LSDV~R}^{2}$ & 0.99 & 0.99 & 0.99 & 0.99 & 0.99 & 0.99 \\
\hline Within $\mathbf{R}^{2}$ & 0.45 & 0.46 & 0.47 & 0.49 & 0.50 & 0.52 \\
\hline Test stat $F_{(13,274)}$ & $211 * * *$ & $212 * * *$ & $217 * * *$ & $223 * * *$ & $227 * * *$ & $237 * * *$ \\
\hline
\end{tabular}

${ }^{a}$ Values shown in parentheses denote HAC standard errors. ${ }^{* * *}$ Significant at $1 \%$ level. $* *$ Significant at $5 \%$ level. *Significant at $10 \%$ level.

The difference between the six models presented in Table 4 relates to how the time series representing policies focused on energy efficiency $(E P)^{3}$ are included in the models. In the basic model, $E P$ are not included at all. In the Delay0 model, they are included for the year in which they were published. For the remaining four models, they are included with delays of 1,3,5, and 7 years, respectively, after publication. This means that, for example, policies introduced in Year 2000 do not have an effect until Year 2007 in the Delay7 model. The reason for presenting the different models is to compare the effects of the introduction of the $E P$ variable with different time delays. If the values shown in Table 4 for $E P$ are instead calculated as percentages then they represent the percentage reductions in demand for the introduction of one new low-impact policy (e.g., -0.0017 expressed as a percentage is $-0.17 \%$.).

\footnotetext{
${ }^{3}$ See the nomenclature and Section 2.2 for descriptions of the EP and other policy-related variables.
} 
The variable coefficients presented in Table 4 have the expected polarities, in the sense that, for example, when price goes up demand is expected to fall. The price $\left(\beta_{1}\right), H D D\left(\beta_{3}\right)$ and Trend $\left(\beta_{5}\right)$ coefficients are found to be significant at the $5 \%$ level for all models. The income $\left(\beta_{2}\right)$ and $C H\left(\beta_{4}\right)$ coefficients are insignificant in all models. Saussay et al. [31] also found the coefficient of income to be insignificant. However, removing Ireland and Portugal from the panel used in the present work resulted in the income elasticity $\left(\beta_{2}\right)$ value increasing to $>0.6$ and becoming significant at the $5 \%$ level $^{4}$. During the period 1990 2010 , these two countries enjoyed large increases in per capita income that were not coupled to any similarly large increases in the use of space heating. It seems that in the absence of economic booms, as experienced in Ireland and Portugal in recent years, the income elasticity for the EU-14 would be higher and significant. Given the lack of statistical significance of the $\mathrm{CH}$ variable the F-form of the Wald test was used to examine the effect on the model of omitting it. It was found that the model was not improved by omitting the $\mathrm{CH}$ variable ${ }^{5}$.The F-test for the combined significance of variables was found to be significant at the $1 \%$ level for all the models.

The absolute values of variable coefficients are also in line with those previously published $[16,31,33$, $50,51]$, with low price elasticities and slightly higher income elasticities, and with a time trend that represents an annual reduction in demand of $>1 \%$ per annum. In a static fixed effects panel of electricity demand in the residential sector of 48 US states for the period 1997-2008, Alberini and Filippini [16] deduced price and income elasticities of -0.22 and 0.28 , respectively. The values are similar to the results obtained in the present study given the differences in explanatory and dependent variables used. Using a dataset that contains 255 observations in the period 1978-1999, Liu [52] found short-term and long-term price elasticities for total energy demand of -0.025 and -0.140 , respectively, for OECD Europe, and shortterm and long-term income elasticities for energy of 0.052 and 0.291 , respectively. These results for longterm elasticities are similar to those found in the present work. Azevedo et al. [34] calculated price elasticities for electricity for the EU of -0.2 , which is similar to the value obtained in the present work. EEW [50] reported that autonomous technical progress brings about a $1 \%$ per annum reduction in demand across the EU, which corresponds with the coefficients calculated for the time trend in Table 4 and Table 5. Overall, in the present study, the price and income, as well as other calculated elasticities seem to conform to what has been reported in the literature.

Although the coefficient of the $E P$ variable is not statistically significant in the Delay0 and Delay 1 models, it is in the subsequent models. It is clear that as time passes the absolute value and statistical significance of the coefficient of the $E P$ variable increase, while those of the Price, Income, and Trend variables decrease. This suggests that initially the impact of $E P$ on demand is negligible compared to

\footnotetext{
${ }^{4}$ Each country was removed in turn from the panel to investigate if there were any significant impacts on $\beta_{1}$ to $\beta_{6}$. The above mentioned finding in relation to income elasticity $\left(\beta_{2}\right)$ was the only major deviation from the results presented in Table 4 found.

${ }^{5}$ The removal of $\mathrm{CH}$ from the model did not change the income elasticity $\left(\beta_{2}\right)$ despite the obvious relationship between $\mathrm{CH}$ and income, i.e. as income rises more households install central heating. The inclusion of $\mathrm{CH}$ in the model can be justified because the installation of $\mathrm{CH}$ has a non-linear impact on heat demand, i.e., the installation of $\mathrm{CH}$ is said to double the heat demand of an average dwelling.
} 
these three other variables but that after a number of years its relative impact increases. During its year of introduction, a low-impact policy reduces demand by $0.071 \%$. This makes sense given that low-impact policies are ranked as those that reduce demand by $<0.1 \%$ (see Section 2.2). After 5 years, the policy impact has tripled to $-0.21 \%$ and become statistically significant.

Given the disparities in the sizes of the 14 countries included in the panel, e.g., Germany and Ireland, a weighted least-squares regression using the same model variables was used to investigate the size effect. For this, the data for each country were weighted by the square root of its population. This weighting was applied to all the variables, with the exceptions of the time trend and the policy variables. The results obtained were very similar to those shown for the non-weighted models in Tables 3 and 4, suggesting that in this case size does not matter.

VIF tests carried out for multicolinearity did not show a VIF value $>6$ for any variable, indicating that multicolinearity is not a problem for the data and model used. Driscoll-Kraay standard errors [53] were calculated to correct for the possible presence of inter-country spatial correlation in the data set. The calculated Driscoll-Kraay standard errors were smaller than the HAC standard errors. Although DriscollKraay standard errors can be biased downwards in small panels, the one used in the present work is in the range suggested by the authors ( $\mathrm{T}>20$ and $\mathrm{N}$ not important), which suggests that for this dataset, spatial correlation is not a problem.

Five different instruments for the $E P$ variable were tested separately to ascertain if the variable was endogenous. The instruments were time series for each country from 1990 to 2010 regarding: 1) the years in which a green political party was in power [54]; 2) the total $\mathrm{CO}_{2}$ emissions [55]; 3) $\mathrm{CO}_{2}$ emissions from the residential sector [55]; 4) gasoline taxes [55]; and 5) average $\mathrm{CO}_{2}$ emissions standards for vehicles ${ }^{6}$ [56]. These five instruments were chosen as possible explanatory variables for the $E P$ variable that were not correlated with energy demand in the residential sector. The idea behind the first three instruments listed was that governments might increase the implementation of efficiency policies as a result of a green party being in government or in reaction to increased $\mathrm{CO}_{2}$ emissions. The idea behind the last two instruments was that a regime change in another sector, e.g., transport, might indicate general energy policy development in an unrelated sector, e.g., housing. To determine if $E P$ was endogenous, it was regressed in a model that included one of the five instruments and the other explanatory variables from Eq. (1). The residuals from this auxiliary regression were then added to Eq. (1) as a new explanatory variable that represents the endogenous part of $E P$. Eq. (1) was then re-run to establish if the endogenous part of $E P$ had statistical significance (Hausman test). This was not found to be the case for any of the five instruments tested, suggesting that $E P$ is not endogenous.

\footnotetext{
${ }^{6}$ Data for $\mathrm{CO}_{2}$ emissions standards for vehicles for the years 1990 to 1994 and 1996 to 1999 were not available and so were interpolated and estimated based on the data that was available for 1995 and 2000 to 2010.
} 
Table 5 : Elasticity coefficients calculated in models of space heating demand per square metre. Compared to Table 4, the Efficiency Policies variable (EP) has been divided into three separate types of policy measures ${ }^{\mathrm{a}, \mathrm{b}}$. The basic model is fitted without any variable for $E P$. The other models include an EP variables without delay $(0)$ and with delays of $1,3,5$, and 7 years respectively.

\begin{tabular}{|c|c|c|c|c|c|c|}
\hline Parameter & Basic Model & Delay0 & Delay1 & Delay3 & Delay5 & Delay7 \\
\hline & $-0.16^{* *}$ & $-0.17 * * *$ & $-0.18 * * *$ & $-0.17 * * *$ & $-0.14 * *$ & $-0.15 * * *$ \\
\hline$\beta_{1}$ (Price) & $(0.077)$ & $(0.057)$ & $(0.049)$ & $(0.048)$ & $(0.061)$ & $(0.057)$ \\
\hline & 0.31 & $0.42 *$ & $0.42 *$ & 0.35 & 0.32 & 0.27 \\
\hline$\beta_{2}$ (Income) & $(0.27)$ & $(0.24)$ & $(0.23)$ & $(0.23)$ & $(0.23)$ & $(0.24)$ \\
\hline & $0.56 * * *$ & $0.62 * * *$ & $0.63 * * *$ & $0.57 * * *$ & $0.54 * * *$ & $0.53 * * *$ \\
\hline$\beta_{3}$ (HDD) & $(0.19)$ & $(0.14)$ & $(0.14)$ & $(0.15)$ & $(0.15)$ & $(0.13)$ \\
\hline & 0.29 & 0.26 & 0.23 & 0.22 & 0.25 & 0.28 \\
\hline$\beta_{4}(\mathbf{C H})$ & $(0.27)$ & $(0.24)$ & $(0.22)$ & $(0.20)$ & $(0.21)$ & $(0.21)$ \\
\hline & $-0.018 * * *$ & $-0.016 * * *$ & $-0.014 * *$ & $-0.013 * * *$ & $-0.014 * * *$ & $-0.013 * *$ \\
\hline$\beta_{5}$ (Trend) & $(0.0053)$ & $(0.0053)$ & $(0.0055)$ & $(0.0047)$ & $(0.0046)$ & $(0.0051)$ \\
\hline Financial Policy & (a) & 0.00069 & 0.00062 & -0.00029 & -0.00071 & $-0.0015 * *$ \\
\hline Financial Pollcy & -- & $(0.0010)$ & $(0.0010)$ & $(0.00082)$ & $(0.00075)$ & $(0.00063)$ \\
\hline & & -0.0012 & -0.0017 & -0.0018 & -0.0027 & -0.0021 \\
\hline Intormative Policy & -- & $(0.0012)$ & $(0.0011)$ & $(0.0015)$ & $(0.0021)$ & $(0.0026)$ \\
\hline Reoulatory Policy & & $-0.0025^{*}$ & $-0.0034 * *$ & $-0.0031 * * *$ & $-0.0030 * * *$ & $-0.0033 * * *$ \\
\hline Regulatory Policy & -- & $(0.0014)$ & $(0.0015)$ & $(0.00095)$ & $(0.00086)$ & $(0.00097)$ \\
\hline$\beta_{0}$ Constant & 31.76 & 25.55 & 21.64 & 21.53 & 23.67 & 22.30 \\
\hline LSDV R ${ }^{2}$ & 0.99 & 0.99 & 0.99 & 0.99 & 0.99 & 0.99 \\
\hline Within $\mathbf{R}^{2}$ & 0.45 & 0.49 & 0.52 & 0.51 & 0.51 & 0.52 \\
\hline Test stat $\mathbf{F}_{(13,272)}$ & $211 * * *$ & $219 * * *$ & $234 * * *$ & $227 * * *$ & $225 * * *$ & $232 * * *$ \\
\hline
\end{tabular}

${ }^{a}$ Since the OLS regressions technique treats each variable independently, the absolute values of some of the coefficients shown in Table 5 are slightly different from those shown in Table 4.

${ }^{\text {b }}$ Values shown in parentheses denote HAC standard errors. ${ }^{* * *}$ Significant at $1 \%$ level. ${ }^{* *}$ Significant at $5 \%$ level. ${ }^{*}$ Significant at $10 \%$ level.

In Table 5, the same models as in Table 4 are presented except that the variable $E P$ is divided into the three policy categories of financial, informative, and regulatory. The polarities and absolute values for the price, income, $H D D, C H$, and trend coefficients in the models shown in Table 5 are similar to those shown in Table 4. However, examining the statistical significance of the coefficients representing the financial, informative, and regulatory policies shows that only the latter is significant in the Delay0 and Delay1 models. This suggests that the coefficient of the $E P$ variable described in the previous paragraph is not significant in the Delay0 and Delay1 models owing to the lack of significance of the impacts of the financial and informative policies. Regulatory policies seem to be the most effective type of energy efficiency policies when the expected impacts, as provided by the MURE Policy Database, are evaluated. The regression coefficients in Table 5 can be interpreted to mean that the introduction of one unit of regulatory policy (i.e., one 'low-impact' policy (See Nomenclature and Section 2.2)) has reduced the energy demand by an average of $0.25 \%$ in the year of introduction. As this is greater than the $<0.1 \%$ impact expected for low-impact policies, it can be concluded that regulatory policies have on average performed better than expected. The results also point to different profiles over time for the three policy types: 
- Regulatory policies have a strong impact already in the year of introduction, and this impact is consistent over the years that follow. This is what would be expected from policies of this type, e.g., building codes with minimum efficiency requirements.

- Financial policies show a low impact in the year of introduction, and require a number of years before they reduce demand by $>0.1 \%$ and reach statistical significance. This might be expected from, for example, subsidies for new technologies whereby more and more house owners adopt the new technology, resulting in a cumulative increase in impact.

- Information policies show the opposite effect, with an increasing coefficient but falling statistical significance after being in force for 1 year. This may be explained by people getting used to information and returning to previous habits and routines after an initial change of behaviour.

The literature on the respective impacts of financial, informative, and regulatory efficiency policies in the residential sector corroborates these findings. Table 5 shows that the correlation between the estimated impact of informative policies from the MURE Policy Database and the savings that actually occurred is low and statistically insignificant. This is similar to previous studies [30, 57], which found that only a small proportion of total annual savings from efficiency at the EU level originated from the effects of information campaigns. In the context of promoting household energy conservation, Steg [58] has reported that information campaigns result in only modest behavioural changes, and von Borgstede et al. [59] has shown that informational policies only give the desired outcomes when households are willing to change wasteful behaviour patterns related to energy use. Yohanis [60] in a survey carried out in Northern Ireland found that although $88 \%$ of surveyed homes had purchased a major appliance in the previous 2 years, only $16 \%$ of the respondents had any idea about the energy ratings of their new appliances. In contrast to these findings, Ek and Söderholm[61] tested the hypothesis that information about available saving measures that is presented in a more concrete and specific way is more likely to affect (stated) behaviour than is more general information. The data they collected from a questionnaire sent to 1200 households in Sweden supported this notion. Lindén et al. [62] reported that following repeated information campaigns, households in Sweden filled washing and dishwashing machines before using them and households in detached houses were more likely to adopt a lower indoor temperature than households in apartments. The findings of various groups [61-64] suggest that there is room for improving the design of information polices, although it should be borne in mind that the willingness to switch to pro-environmental behaviours depends on the levels of the perceived thresholds that have to be overcome [59].

The results of interviews with experts and NEEAP screenings [50] revealed enormous disparity across Member States in terms of the levels of ambition of their energy efficiency policies and that in the lessprogressive countries many experts consider the first EPBD [6] to be a milestone that catalyses a new legal framework for energy use in buildings. Of the portfolio of policy measures in place across the EU, the IEA [64] reported that up to now the EPBD (categorised as an information policy in this work) has been the policy instrument with the greatest potential impact on energy efficiency in existing residential buildings in the short-term ( 5-10-year period) or even in the medium-term up to Year 2020. As the EPBD 
[6] was, for example, only proscribed in Austria in 2008, it is too early to state definitively what its effect on demand will be and whether it will be a transformative agent, given that it seems to have brought energy efficiency in buildings into the political agenda.

With regard to financial policies, Nauleau [65] used a panel of over 23,000 French households to analyze the impact of the introduction of a tax credit in 2005; no significant impact was noted for the first 2 years of the scheme, although this changed after 2007. Boonekamp et al. [57] reported that across the EU a substantial number of new measures for funding (40\%) were introduced after the Energy Services Directive [7] came into force (post-2006). This suggests that it may be also too early to say what the effects of such policies are. However, Filippini et al. [30] found financial policies to be the policy type with the greatest impact in terms of reducing demand. Their study covered total energy demand in the residential sector, i.e., including electricity for appliances and lighting, for $27 \mathrm{EU}$ countries in the period 1996-2009. The main difference between their results and the present results is that we show that the financial policies have an impact a number of years after they are introduced. Tietenberg et al. [21] reported that the literature makes it quite clear that any second-best policy mix in the face of bounded rationality non-optimising behaviour and volatile prices must recognize a role for more prescriptive strategies, such as targeted subsidies, efficiency standards, and/or tradable white certificates. The prescriptive nature of regulatory policy may be the reason why this policy type shows the greatest effect in the present work. The findings of several groups $[15,25,26,28,31,32]$ reinforce the results of the present paper in demonstrating that regulations are most effective.

\subsection{Implication of calculated coefficients}

For the EU-14 overall, the average percentage increase in energy prices between 1990 and 2010 has been $1 \%$ per year (this value encompasses the increases and decreases in prices over the period, as shown in Figure 2). The average percentage increase in income for the same period has been $2 \%$. If the coefficients calculated in the present work (Table 4 and Table 5) were to persist after 2010 one could expect that a $1 \%$ rise in the price of energy would result in a $0.15 \%$ fall in demand ceteris paribus. If at the same time, income would increase by only $1 \%$ per annum (half the rate seen in the previous decades), this would offset the energy savings resultant from higher prices. The penetration of central heating has been steady at $1 \%$ per year for the period $1990-2010$, although as this is approaching saturation, i.e., $>90 \%$ penetration in most countries, the same rate of growth cannot be expected in the future. Regardless of price and income dynamics or the impact of policy, demand can be expected to fall by a compounded $1 \%$ per year, due to factors represented by the time trend (autonomous technical progress, fuel switching, and structural effects). While autonomous technical progress and fuel switching from direct electric heating, oil heating and solid fuels heating to district heating, renewables ${ }^{7}$ and natural gas heating can be expected to continue in the coming decades, future structural effects are less clear. During the period 1990-2010, increasing indoor temperatures would have diluted the effects of efficiency as represented by the time trend. Going forward, this effect should be diminished as homes converge on a standard indoor temperature of around

\footnotetext{
${ }^{7}$ As noted earlier, while the use of renewables in dwellings may not reduce heating demand per se, it reduces final energy demand, as represented in national statistics.
} 
$21^{\circ} \mathrm{C}$. However, the effects of people spending more time at home, e.g., more retirees and more people working from home, could have a similar diluting effect ${ }^{8}$. Nonetheless, two of the aforementioned factors represented by the time trend (autonomous technical progress and fuel switching) should continue to reduce demand apace.

The results of the present work also show that regulatory policies reduced demand for space heating by around $0.3 \%$ for each low-impact policy introduced. Given that medium-impact and high-impact policies are assumed to have ten and twenty times, respectively, the impact of low-impact policies (See Section 2.2

8 ), this suggests that the introduction of such regulatory policies would reduce demand by $3 \%$ and $6 \%$, respectively ${ }^{9}$. It should be borne in mind that such large impacts reflect the fact that such policies are not introduced very often (e.g. for Austria. there was only one high-impact and one medium-impact regulatory policy introduced between 1990 and 2010; Table 3 ) and they represent the averages for a wide variety of regulatory policy impacts across the 14 countries studied. Therefore, it may be the case that the data representing the policies are too disparate for a strong emphasis to be placed on the calculated values. Thus, the differences in magnitudes of the three policy categories may be of more interest than the numbers themselves. EEW [50] advocates a savings target of $2 \%$ per annum, composed of a combination of efficiency policies and autonomous technical progress, based on the idea that savings of $1 \%$ per annum are already being made and that this should be doubled. The numerical results from the present work suggest that this can be achieved through the introduction of more or stronger regulatory policies (e.g., the introduction of an additional medium-rank policy every 3 years or an additional high-rank policy every 6 years). However, given the uncertainty related to the exact impact of policies on savings, the message from this paper for policymakers is to increase either the ambition level or the number of regulatory policies in force.

A Laspeyres decomposition [66,67 and Nomenclature] was carried out to examine the effects of individual model variables on energy demand $\left(\mathrm{kWh} / \mathrm{m}^{2} /\right.$ year). For this, the model coefficients of the Delay 3 model shown in Table 6 (chosen as a representative model) were multiplied by the respective time series data for 1990 used in their calculation, except that each variable was in turn changed to its 2010 value (while keeping the other time series data at 1990 values), to isolate their effects on demand relative to those of the other variables. The time series variables used for the decomposition for 1990 and 2010 were the averages for each variable for the $14 \mathrm{EU}$ countries. Table 6 shows the magnitude that each model variable increased or decreased demand in 2010 relative to 1990. The impact on demand of the time trend, which represents autonomous technical progress, fuel switching, and structural effects, stands out as it accounts for $>20 \%$ of the change. Energy efficiency policies resulted in an approximately $11 \%$ reduction most of which was as a result of regulatory and informative policies. Energy price increases were modest during

\footnotetext{
${ }^{8}$ The structural effects of trends in larger dwellings are not considered because the dependent variable examined is unit consumption, while the structural effects of longer daily and annual heating duration and increased indoor temperature are included in the unit consumption variable. These latter effects cannot however be examined explicitly due to the scarcity of relevant time series of data.

${ }^{9}$ Note that because of the way in which the analysis in the present work has been carried out, this would mean individual regulatory policies across the 14 countries would collectively give these percentages.
} 
this period and decreased energy demand by less than 3\%. At the same time, income dynamics increased demand by over $10 \%$. This corresponds to the pre-financial crisis period of economic growth in the EU. The introduction of $\mathrm{CH}$ increased demand by approximately $4 \%$, while a number of colder-than-average winters increased demand by over $10 \%$.

Table 6: Examination of impacts of model variables on demand between 1990 and 2010 made using a Laspeyres Decomposition.

\begin{tabular}{|l|r|}
\hline \multicolumn{1}{|c|}{ Variable } & \multicolumn{1}{c|}{ Impact 1990 - 2010 } \\
\hline Price & Decrease by $2.8 \%$ \\
\hline Income & Increase by $11.9 \%$ \\
\hline Climate (HDD) & Increase by $10.6 \%$ \\
\hline Central Heating & Increase by $4.4 \%$ \\
\hline Time Trend & Decrease by $22.9 \%$ \\
\hline Financial Policies & Decrease by $0.5 \%$ \\
\hline Information Policies & Decrease by $5.0 \%$ \\
\hline Regulatory Policies & Decrease by $5.8 \%$ \\
\hline Total Change (sum of above) & Decrease by $10.1 \%$ \\
\hline Total Change (measured) & Decrease by $13.8 \%$ \\
\hline Laspeyres Decomposition Residual & Decrease by $3.7 \%$ \\
\hline
\end{tabular}

\section{$4 \quad$ CONCLUSIONS}

The effects of energy efficiency policies on space heating in the EU residential sector were analysed using a fixed effects static panel data model for the period 1990-2010. This analysis was performed using unit consumption of energy for space heating $\left(\mathrm{kWh} / \mathrm{m}^{2} /\right.$ year), which is an established indicator of efficiency. The impacts of three specific categories of efficiency-focused policy, namely financial, regulatory, and informative, were also examined. The results show that in relation to the ex-ante evaluations of impacts, the regulatory policies have been more effective at reducing demand than have the informative and financial policies. In addition, regulatory policies are found to have a consistent demand-reducing impact over time, as compared with informative and financial policies. Informative policies are found to have a more short-term impact, whereas financial policies require a number of years to have an effect. Although the EU EPBD and ESD policy packages may improve the effects of information and financial policies, the indications to date, which are supported by the findings of the present work, are that regulatory policies reduce demand in the year in which they are introduced and for at least 7 years thereafter. These findings suggest that regulatory policy measures should be assigned a high priority if EU-wide energy goals are to be met expeditiously. This conclusion is supported by the well-known market barriers to efficiency that exist in the residential sector, which, in contrast to information- or financial efficiency-focused policies, necessitate regulation to be overcome. It also reinforces the findings of the recent literature on the topic [30-32]. 


\section{Acknowledgements}

This work is co-funded by two projects; Pathways to a Sustainable European Energy System and; Pathways to a Sustainable European Energy System - Svenska Systemlösningar (Swedish Energy Agency). The authors thank Vincent Collins, Franck Nadaud, and Magnus Söderberg for valuable suggestions related to the work.

\section{REFERENCES}

[1] EC. A Roadmap for moving to a competitive low carbon economy in 2050. COM(2011)112: European Commission; 2011.

[2] EC. Energy efficiency: delivering the 20\% target. COM(2008)772: European Commission; 2008.

[3] EC. Action plan for energy efficiency: realising the potential. COM(2006)545. European Commission; 2006.

[4] ECF. Energy savings 2020: How to triple the impact of energy saving policies in Europe. European Climate Foundation; 2011.

[5] Euraktiv News. Lidegaard: 'We fought like lions for the Energy Efficiency Directive'. 2012 $<\mathrm{http}$ ://www.euractiv.com/energy-efficiency/lidegaard-fought-lions-energy-ef-news$513304>$.

[6] EC. Directive 2002/91/EC of the European Parliament and of the Council of 16 December 2002 on the energy performance of buildings.: European Commission; 2002.

[7] EC. Directive 2006/32/EC of the European Parliament and of the Council of 5 April 2006 on energy end-use efficiency and energy services and repealing Council Directive 93/76/EEC. European Commission; 2006.

[8] EC. Directive 2009/125/EC of the European Parliament and of the Council establishing a framework for the setting of ecodesign requirements for energy-related products: European Commission; 2009.

[9] EC. Directive 2010/30/EU of the European parliament and of the council of 19 May 2010 on the indication by labelling and standard product information of the consumption of energy and other resources by energy-related products (recast). European Commission; 2010.

[10] EC. Directive 2010/31/EU of the European Parliament and of the Council of 19 May 2010 on the energy performance of buildings (recast). European Commission; 2010.

[11] EC. Directive 2012/27/EU of the European Parliament and of the Council of 25 October 2012 on energy efficiency, amending directives 2009/125/EC and 2010/30/EC and repealing directives 2004/8/EC and 2006/32/EC. European Commission; $2012 .$.

[12] EC. Energy taxation: Commission promotes energy efficiency and more environmental friendly products. IP(11)468: European Commission; 2011.

[13] ISIS. MURE II Database on energy efficiency policies and measures. Rome, Italy: ISIS; $2012<\mathrm{http}: / /$ www.measures-odyssee-mure.eu/> .

[14] Uihlein A, Eder P. Policy options towards an energy efficient residential building stock in the EU-27. Energy and Buildings. 2010;42:791-8 http://dx.doi.org/10.1016/j.enbuild.2009.11.016

[15] Geller H, Harrington P, Rosenfeld AH, Tanishima S, Unander F. Polices for increasing energy efficiency: Thirty years of experience in OECD countries. Energy Policy. 2006;34:556-73. http://dx.doi.org/ 10.1016/j.enpol.2005.11.010 
[16] Alberini A, Filippini M. Response of residential electricity demand to price: The effect of measurement error. Energy Economics. 2011;33:889-95. http://dx.doi.org/10.1016/j.eneco.2011.03.009

[17] Convery FJ. Reflections-Energy Efficiency Literature for Those in the Policy Process. Review of Environmental Economics and Policy. 2011;5:172-91. http://dx.doi.org/10.1093/reep/req026

[18] Gillingham K, Newell RG, Palmer K. Energy Efficiency Economics and Policy. Annual Review of Resource Economics. 2009;1:597-620. http://dx.doi.org/10.1146/annurev.resource.102308.124234

[19] Neij L. Barriärer och styrmedel för en effektivare energianvändning [Barriers and Measures for a more efficient use of energy]. University of Lund, Sweden. 2007. In Swedish.

[20] Ryan L, Moarif S, Levina E, Baron R. Energy efficiency policy and carbon pricing. Paris, France: IEA; 2011.

[21] Tietenberg T. Reflections-Energy Efficiency Policy: Pipe Dream or Pipeline to the Future? Review of Environmental Economics and Policy. 2009;3:304-20. http://dx.doi.org/10.1093/reep/rep004

[22] IEA/UNDP. Modernising Building Energy Codes - to Secure our Global Energy Future. Paris, France: IEA; 2013.

[23] de T'Serclaes P, Jollands N. Mind the gap: quantifying principal-agent problems in energy efficiency. Paris, France: IEA; 2007.

[24] Joskow PL. Energy Policies and their consequences after 25 years. The Energy Journal 2003;4. http://dx.doi.org/10.5547/ISSN0195-6574-EJ-Vol24-No4-2

[25] Ademe. Energy Efficiency Monitoring in the EU. Paris, France: Ademe Editions; 2005.

[26] Vine E, du Pont P, Waide P. Evaluating the impact of appliance efficiency labeling programs and standards: process, impact, and market transformation evaluations. Energy. 2001;26:1041-59. http://dx.doi.org/10.1016/S0360-5442(01)00053-6

[27] Hoicka CE, Parker P, Andrey J. Residential energy efficiency retrofits: How program design affects participation and outcomes. Energy Policy 2014: 65;594-607. http://dx.doi.org/ 10.1016/j.enpol.2013.10.053

[28] Ürge-Vorsatz D, Koeppel S, Mirasgedis S. Appraisal of policy instruments for reducing buildings' $\mathrm{CO}_{2}$ emissions. Building Research \& Information. 2007;35:458-77. http://dx.doi.org/ 10.1080/09613210701325883

[29] Horowitz M. Changes in electricity demand in the United States from the 1970s to 2003. The Energy Journal. 2007; 3. http://dx.doi.org/10.5547/ISSN0195-6574-EJ-Vol28-No3-6

[30] Filippini M, Hunt L, Zorić J, 2014. Impact of energy policy instruments on the estimated level of underlying energy efficiency in the EU residential sector. Energy Policy 2014; 69:73-81. http://dx.doi.org/10.1016/j.enpol.2014.01.047

[31] Saussay A, SahebY, Quirion P, 2012.The impact of building energy codes on the energy efficiency of residential space heating in European countries - a stochastic frontier approach. In: International Energy Program Evaluation Conference,12-14 June 2012, Rome, Italy.

[32]Bigano A, Arigoni-Ortiz R, Markandya A, Menichetti E, Pierfederici R. The linkages between energy efficiency and security of energy supply in Europe. In: Galarraga I, González-Eguino M, Markandya A (Eds.), Handbook of Sustainable Energy, Edward Elgar Publishing Ltd., Northampton (2011), pp. 60-83.

[33] Haas R, Schipper L. Residential energy demand in OECD-countries and the role of irreversible efficiency improvements. Energy Economics. 1998;20:421-42. http://dx.doi.org/ 10.1016/S0140-9883(98)00003-6 
[34] Azevedo IML, Morgan MG, Lave L. Residential and Regional Electricity Consumption in the U.S. and EU: How Much Will Higher Prices Reduce CO2 Emissions? The Electricity Journal. 2011;24:21-9. http://dx.doi.org/10.1016/j.tej.2010.12.004

[35] Espey JA, Espey M. Turning on the Lights: A Meta-Analysis of Residential Electricity Demand Elasticities. Journal of Agricultural and Applied Economics. 2004;36:17.

[36] Lee C, Lee J. A Panel Data Analysis of the Demand for Total Energy and Electricity in OECD Countries. The Energy Journal. 2010;1. http://dx.doi.org/10.5547/ISSN0195-6574EJ-Vol31-No1-1

[37] Narayan PK, Smyth R, Prasad A. Electricity consumption in G7 countries: A panel cointegration analysis of residential demand elasticities. Energy Policy. 2007;35:4485-94. http://dx.doi.org/10.1016/j.enpol.2007.03.018

[38] Nerlove M, Sevestre P, Balestra P. Introduction. In: Mátyás L, Sevestre, P.(Eds.). The Econometrics of Panel Data - Fundamentals and Recent Developments in Theory and Practice. Third Edition ed. Berlin Heidelberg: Springer-Verlag 2008.

[39] Dougherty C. Introduction to Panel Data Models. Introduction to Econometrics Fourth Edition ed. UK: Oxford University Press; 2011.

[40] Berry D. The impact of energy efficiency programs on the growth of electricity sales. Energy Policy. 2008;36:3620-5. http://dx.doi.org/10.1016/j.enpol.2008.06.011

[41] Vedung, E. Policy instruments: Typologies and theories. In M.-L. Bemelmans-Videc, R. C. Rist, \& E. Vedung (Eds.), Carrots, sticks, and sermons: Policy instruments and their evaluation (pp. 21-58). New Brunswick, NJ: Transaction; 2008.

[42] Yearwood- Travezan J, Harmsen R, van Toledo G. Policy analysis for energy efficiency in the built environment in Spain. Energy Policy. 2013;61:317-26. http://dx.doi.org/10.1016/j.enpol.2013.05.096

[43] Enerdata. Odyssee Database. Enerdata, Grenoble, France; $2012<$ http://www.odysseeindicators.org/>.

[44] OECD. Economic Outlook No 84: Annual and Quarterly data. Paris, France: OECD; 2008.

[45] Eurostat. HICP - all items - annual average indices, 2013 $<\mathrm{http}$ ://ec.europa.eu/eurostat/tgm/table.do?tab=table\&init $=1 \&$ language $=$ en $\&$ pcode $=$ tec 00 $027 \&$ plugin $=1>$.

[46] Werner S. European DH Prices 1980-2009. 2009. Personal Communication to author.

[47] IEA. IEA Energy Prices and Taxes Statistics, OECD iLibrary. Paris, France: IEA; 2012. http://dx.doi.org/10.1787/eneprice-data-en

[48] Werner S. Ecoheatcool 2005-2006, Work packages 1 (The European heat market) and 4 (Possibilities with more district heating in Europe). Brussels, Belgium: Euroheat and Power; 2006.

[49] Ó Broin E, Mata É, Nässén J, Johnsson F. Quantification of the Energy Efficiency Gap in the Swedish Residential Sector. Energy Efficiency. 201. http://dx.doi.org/10.1007/s12053-015-9323-9

[50] EEW. Improving and implementing national energy efficiency strategies in the EU framework. Energy Efficiency Watch; 2013. <http://energy-efficiencywatch.org/fileadmin/eew_documents/images/Event_pictures/EEW2_Logos/EEWFinal_Report.pdf $>$.

[51] Nässén J, Sprei F, Holmberg J. Stagnating energy efficiency in the Swedish building sector-Economic and organisational explanations. Energy Policy. 2008;36:3814-22. http://dx.doi.org/10.1016/j.enpol.2008.07.018

[52] Liu G. Estimating energy demand elasticities for OECD countries: a dynamic panel data approach: Statistisk Sentralbyrå Oslo, Norway; 2004. 
[53] Driscoll J, Kraay A. Spatial Correlations, A correction for spatial correlation in panel data. Policy research working paper 1553.The World Bank Policy Research Department, 1995.

[54] Wikipedia, Wikipedia pages of Green Parties of 14 Countries included in this study. 2015 e.g.<http://en.wikipedia.org/wiki/Green_Party_\%28Ireland\%29\#In_government> [accessed 27th January, 2015].

[55] IEA, IEA Online Data Services, IEA, Paris, France. $2015<$ http://data.iea.org/> [accessed January, 2105].

[56] Eurostat, Average carbon dioxide emissions per $\mathrm{km}$ from new passenger cars, 2015 $<$ http://ec.europa.eu/eurostat/web/products-datasets/-/tsdtr450 $>$ [accessed 27th January, 2015].

[57] Boonekamp P, Vethman P, Gerdes J, Sipma J, Feenstra Y, Pollitt H, et al. Background study for horizontal issues concerning energy savings in the EU. Request for Services, TREN/A2/143-2007. Energy Research Centre of the Netherlands and Cambridge Econometrics. 2011.

[58] Steg L. Promoting household energy conservation. Energy Policy. 2008;36:4449-53. http://dx.doi.org/10.1016/j.enpol.2008.09.027

[59] von Borgstede C, Andersson M, Johnsson F. Public attitudes to climate change and carbon mitigation-Implications for energy-associated behaviours. Energy Policy. 2013;57:18293. http://dx.doi.org/10.1016/j.enpol.2013.01.051

[60] Yohanis YG. Domestic energy use and householders' energy behaviour. Energy Policy. 2012;41:654-65. http://dx.doi.org/10.1016/j.enpol.2011.11.028

[61] Ek K, Söderholm P. The devil is in the details: Household electricity saving behavior and the role of information. Energy Policy. 2010;38:1578-87. http://dx.doi.org/10.1016/j.enpol.2009.11.041

[62] Lindén A-L, Carlsson-Kanyama A, Eriksson B. Efficient and inefficient aspects of residential energy behaviour: What are the policy instruments for change? Energy Policy. 2006;34:1918-27. http://dx.doi.org/10.1016/j.enpol.2005.01.015

[63] kristom, B. Residential Energy Demand. Volume 1: ENERGY - Reference Module in Earth Systems and Environmental Sciences. Encyclopedia of Energy, Natural Resource, and Environmental Economics.2013, Pages 218-24. http://dx.doi.org/10.1016/B978-0-12375067-9.00097-8

[64] IEA. Promoting Energy Efficiency Investments - Case Studies in the Residential Sector. Paris, France: IEA; 2008.

[65] Nauleau, M.L. Free-riding on tax credits for home insulation in France: An econometric assessment using panel data. Energy Economics.2014; 46: 78-92. http://dx.doi.org/10.1016/j.eneco.2014.08.011

[66] IEA. Indicators of Energy Use and Efficiency - Understanding the link between energy and human activity. Paris, France: IEA; 1997.

[67] Ó Broin, E.. Energy Demands of European Buildings: A Mapping of Available Data, Indicators and Models. Master Thesis, Chalmers University of Technology Report No. T2007-307, Göteborg, Sweden; 2007 $<$ http://publications.lib.chalmers.se/publication/136409>. 